\title{
VRŠNJAČKI ODNOSI NA PREDŠKOLSKOM UZRASTU I USLOVI PODSTICANJA POZITIVNE VRŠNJAČKE INTERAKCIJE
}

\begin{abstract}
Apstrakt
Dete doživljava svet kroz odnose koje uspostavlja i razvija. Odnosi sa bliskim odraslim osobama i odnosi sa vršnjacima određuju njegov razvoj i učenje u ranom detinjstvu. Vršnjačka interakcija je od suštinskog značaja za aktuelno i buduće psihosocijalno prilagođavanje. Vršnjaci pomažu detetu da savlada nove društvene veštine $i$ da se upozna sa socijalnim normama i procesima uključivanja u međuljudske odnose. Ova tema je od posebnog interesa danas kada je sve veći broj dece izložen vršnjacima još mnogo pre školskog uzrasta, kroz vrtiće. Međutim, sama činjenica da deca veliki deo vremena provode zajedno ne znači i da će razviti veštine pozitivne interakcije. $U$ tom kontekstu značajna uloga pridaje se odrasloj osobi tj. vaspitaču. Uloga vaspitača je da kroz kreiranje fizičkog $i$ socijalnog okruženja, koristeći različite strategije, kao $i$ sopstveni primer, podstiče pozitivnu vršnjačku interakciju.
\end{abstract}

Ključne reči: vršnjaci, odnosi, interakcija, vapitač, predškolski uzrast

\section{Uvod}

Postoje brojne studije o važnosti i uticaju vršnjačke interakcije na razvoj pojedinca. Međutim, one se manje ili više odnose na srednje detinjstvo i adolescenciju, dok je manji broj istraživanja koja se bave problematikom vršnjačkih odnosa na ranom uzrastu. Smatra se da je teško izvući zaključke o razvojnim posledicama ranih interakcija sa vršnjacima. Takođe, složenost u vršnjačkim interakcijama, kao i mnoga ograničenja u primeni metoda i mera, na uglavnom neverbalno interaktivnoj deci, može otežati pouzdano istraživanje ranih vršnjačkih interakcija u odnosu na kasnije životne faze.

${ }^{1}$ aleksandra.pavlovic@ff.uns.ac.rs 
Ipak, neke teorijske osnove za moderna istraživanja o vršnjačkim odnosima dece mogu se pratiti od prvih decenija dvadesetog veka. Piaget (1932) je u svojim ranim radovima tvrdio da se odnosi dece sa vršnjacima mogu jasno razlikovati od njihovog odnosa sa roditeljima (prema Rubin, Bowker, McDonald, \& Menzer, 2013). Odnosi odraslih i dece posmatrani su kao vertikalni, gde postoji dominacija i potvrda moći odraslog. Deca prihvataju pravila odraslih, ne nužno zato što ih razumeju, već zato što se od njih očekuje poslušnost. Suprotno tome, vršnjački odnosi dece prikazani su kao uravnoteženi i egalitarni, horizontalni. S obzirom na takvu pretpostavljenu jednakost u vršnjačkoj interakciji, deca mogu da dožive priliku za ispitivanje sukobljenih ideja i objašnjenja, pregovaranje i raspravljanje o više perspektiva i odlučivanje na kompromis ili odbacivanje ideje svojih vršnjaka (Rubin, Bowker, McDonald, \& Menzer, 2013).

Takođe, određen doprinos uticaju vršnjaka dala je teorija socijalnog učenja Alberta Bandure koja se zasniva na ideji da se učenje odvija kroz interakciju sa drugima, u socijalnom kontekstu. Posmatrajući ponašanje drugih ljudi mi razvijamo slično ponašanje. Nakon posmatranja ponašanja drugih, ljudi asimiliraju i imitiraju to ponašanje, posebno ako su njihova iskustva posmatranja pozitivna ili uključuju nagrade vezane za posmatrano ponašanje (Bandura, 2002). Osnovno načelo teorije socijalnog učenja je da deca uče o svojim socijalnim okruženjima, i kako se ponašati u ovim kontekstima, direktnim vršnjačkim nadzorom i indirektnim posmatranjem ponašanja vršnjaka. Iz ove perspektive, vršnjaci se posmatraju kao kontrola ponašanja i agensi za promenu ponašanja. U tom pogledu, deca kažnjavaju ili ignorišu ne-normativno društveno ponašanje i nagrađuju ili pozitivno pojačavaju ona ponašanja koja se smatraju kulturno prikladnim. Zapravo, tvrdi se da samo posmatranje socijalne nagrade/kazne, kao posledica određenog ponašanja, može igrati značajnu ulogu u socijalnom učenju (Shortt, Capaldi, Dishion, Bank, \& Oven, 2003).

Pored toga, prema teoriji grupne socijalizacije grupa vršnjaka igra značajniju ulogu od roditelja u ličnosti i društvenom razvoju dece. Deca jednom kada se nađu izvan kuće, prilagode se i slede prevladavajuće norme u grupama u kojima provode svoje vreme, a grupe uglavnom čine druga deca, tj. vršnjaci (Collins, Maccoby, Steinberg, Hetherington, \& Bornstein, 2000).

\section{Karakteristike vršnjačkih odnosa na predškolskom uzrastu}

Većina dece se već na najranijem uzrastu redovno susreće sa vršnjacima. Do šest meseci starosti, novorođenčad mogu komunicirati sa drugom decom osmehom, dodirivanjem, dok u drugoj godini života deca pokazuju i prosocijalno i agresivno ponašanje prema vršnjacima (Rubin, Burgess, Dwyer, \& Hastings, 2003).

U osnovi sposobnosti harmonične interakcije sa vršnjacima su emocionalne, kognitivne i bihejvioralne veštine, kao što su: regulisanje emocija, inhibiranje impulsa, oponašanje tuđih postupaka, razumevanje uzročno-posledičnih veza i jezička kompe- 
tentnost (Hay, Payne, \& Chadwick, 2004). Deficiti u ovim veštinama mogu se nadoknaditi kada deca komuniciraju sa kompetentnim odraslim osobama, poput roditelja ili vaspitača, međutim, vršnjaci koji takođe i sami postepeno razvijaju ove veštine mogu biti manje tolerantni, pa tako i vršnjačko okruženje može biti posebno izazovno. Deca sa smetnjama u razvoju koja imaju nedovoljno razvijene prethodno pomenute veštine mogu biti izložena posebnom riziku, što može predstavljati problem u odnosu sa vršnjacima (Rogers, Hepburn, Stackhouse, \& Wehner, 2003).

Istraživanja odnosa sa vršnjacima u ranom detinjstvu koriste sociometrijske metode u kojima deca imenuju vršnjake koje vole i (ponekad) ne vole. Ove metode pokazuju da su neka deca prihvaćena od strane svojih vršnjaka, dok druge aktivno ili odbijaju ili ignorišu. Na vršnjačko prihvatanje utiču mnogi faktori u detetovom životu, poput njihovih odnosa u kući sa roditeljima, braćom i sestrama, roditeljskog odnosa i nivoa socijalne podrške porodice (Ostrov, \& Keating, 2004). Međutim, na vršnjačko prihvatanje/odbijanje najviše direktno utiče sopstveno ponašanje dece. Studije pokazuju da visoko agresivna deca nisu prihvaćena od strane vršnjaka, kao i da vršnjačko odbijanje može prouzrokovati i odsustvo prosocijalnog ponašanja, bez manifestovanja agresivnog ponašanja (Vaughn, Vollenweider, Bost, Azria-Evans, \& Snider, 2003). Zapravo, dečja upotreba prosocijalnog ponašanja sa vršnjacima služi za poboljšanje njihovog društvenog statusa u grupi, a to zauzvrat može delovati kao zaštitni faktor protiv budućeg odbijanja od strane vršnjaka. Pored toga, deca sa višim nivoom prosocijalnog ponašanja obično učestvuju u nižim nivoima agresije i uopšteno će doživeti manje odbacivanja od strane vršnjaka. Stoga, dugotrajna upotreba prosocijalnog ponašanja može olakšati interakciju među vršnjacima, veće prihvatanje od strane vršnjaka i veći socijalni status u vršnjačkoj grupi.

U literaturi o vršnjačkim odnosima prijateljstvo se definiše kao blizak odnos dva pojedinca (Rubin, Bukowski, \& Parker, 2006). Za razliku od veze roditelj-dete i drugih porodičnih veza (npr. rodbinski odnosi), prijateljstva se smatraju dobrovoljnim vezama, jer se obe strane dobrovoljno uključuju u vezu. Primarna karakteristika prijateljstva je da je ono recipročne prirode. „Pravo“ prijateljstvo može postojati samo kada obe osobe vide jedno drugo kao prijatelja. Iako slične karakteristike (npr. rasa, pol), ponašanja (npr. agresija) i interesovanja mogu imati uticaja u odabiru prijatelja, međusobna naklonost smatra se osnovom prijateljstva (Rubin, Bukovski, \& Parker, 2006).

Istraživanja su pokazala da se specifične funkcije prijateljstva razlikuju u različitim fazama razvoja (Rubin, Bukovski, \& Parker, 2006). Pa tako, tokom ranog detinjstva, prijateljstva pružaju deci mogućnost za prijatnu igru i pomoć u regulisanju svog ponašanja. Kasnije, prijateljstva pružaju deci mogućnost da nauče o normama ponašanja i emocija, nude emocionalnu i socijalnu podršku, pružaju pomoć i priliku za razvoj potrebnih socijalnih veština koje će im koristiti tokom čitavog života. Takođe, tokom kasnog detinjstva i rane adolescencije prijateljstvo pruža mogućnost za izražavanje i regulisanje afekta i igra važnu ulogu u uspešnom razvoju identiteta (Burgess et al., 2006). 
Već predškolska deca, slično kao i adolescenti, manifestuju svoje ponašanje u odnosu na to da li su u interakciji sa prijateljima ili manje bliskim vršnjacima. Na primer, najbolji prijatelji predškolskog uzrasta se više angažuju u međusobnu interakciju i interaktivnije i složenije igranje kada su u interakciji jedni sa drugima nego sa drugim vršnjacima. Slično tome, opservacijsko istraživanje pokazalo je da deca ispoljavaju više pozitivno ponašanje (npr. pozitivno reagovanje, pokazivanje pozitivnog uticaja) i više sofisticiranosti u igri (npr. angažman u igri fantazije i igri koju karakteriše pregovaranje) pri interakciji sa prijateljima nego drugim vršnjacima (Simpkins, \& Parke, 2002).

Pored toga, sukobi između prijatelja obično su manje intenzivni od onih između vršnjaka. Prijatelji će verovatnije rešiti sukob, često koristeći strategije rešavanja sukoba, kao što su pregovori i kompromis koji pomažu da im prijateljstvo traje i nastavi se u budućnosti (Simpkins i Parke, 2002). Dakle, prijateljstva već tokom ranog detinjstva pružaju siguran relacijski kontekst ne samo za pozitivnu, prijatnu interakciju, već i za uspešno rešavanje sukoba.

\section{Ishodi pozitivne vršnjačke interakcije}

Za dete je veoma važna mogućnost da ostvari interakciju sa vršnjacima, mlađom i starijom decom, da učestvuje u zajedničkim aktivnostima i izgrađuje prijateljstva. Vršnjaci su izvor podrške i izazova i dete mora naučiti da integriše pripadništvo vršnjačkoj grupi (da sledi, prihvata i sarađuje) sa drugim aspektima vršnjačkih odnosa, kao što su takmičenje, preuzimanje vođstva i razrešavanje konflikata. Kroz zajedničke praktične životne aktivnosti i igru sa vršnjacima mala deca uče jedni od drugih kako da dele, kako da razumeju i uzimaju u obzir potrebe i očekivanja drugih i uvažavaju tuđe mišljenje i stanovište, kako da kontrolišu vlastite impulse i razrešavaju konflikte. Takođe, kroz odnose sa vršnjacima deca preispituju vlastiti identitet, uočavaju snagu i slabosti kod sebe i drugih, preuzimaju nove uloge i odgovornosti i razvijaju osećanje pripadanja i prihvaćenosti (Pavlović Brenesalović, Krnjaja, 2017).

Kada je reč o ishodima vršnjačke interakcije postoje jasne veze između vrlo ranih odnosa sa vršnjacima i onih koji se javljaju kasnije u detinjstvu. Na primer, deca koja su na ranom uzrastu bila u stanju da se uključe u složenu igru sa vršnjacima bila su kompetentnija u radu sa drugom decom u predškolskim godinama i u srednjem detinjstvu. Prihvatanje vršnjaka u ranom detinjstvu prediktor je kasnijeg odnosa sa vršnjacima (Ladd, \& Troop-Gordon, 2003). Međutim, nije jasno da li rani problemi sa vršnjacima zapravo uzrokuju kasnije socijalne probleme ili su oba uzrokovana drugim faktorima rizika, u kući i/ili školi i nerazvijenim veštinama koje otežavaju prihvatanje svojih vršnjaka.

Neki od opštih ciljeva predškolskog vaspitanja i obrazovanja, kao i ključne obrazovne kompetencije za celoživotno učenje podrazumevaju: srećno, zadovoljno, ostvareno i prihvaćeno dete, koje gradi odnose poverenja, uvažavanja, bliskosti i pri- 
jateljstva, kao i razvijanje komunikacijske kompetencije i sposobnosti, posebno u vršnjačkoj komunikaciji (Pavlović Breneselović, Krnjaja, 2017). U tom kontekstu važnost vršnjačke komunikacije u predškolskom detinjstvu je očigledna. Ona može imati povoljan uticaj na razvijanje kognitivnih veština, prosocijalno ponašanje i emocionalnu udobnost. Pored toga, komunikacija je prediktor kognitivnog razvoja. Štaviše, vršnjačka komunikacija podstiče prosocijalno ponašanje, sprečava nasilje i doprinosi povoljnoj emocionalnoj klimi.

Dakle, pozitivne socijalne veštine koje deca primenjuju u interakciji sa vršnjacima već na ranom uzrastu mogu dovesti do razvoja pozitivnih odnosa sa vršnjacima, prihvatanja i prijateljstva. Iako mnoga deca prirodno razvijaju ove pozitivne socijalne veštine, neka deca to ne čine. Deca koja su povučena kao i deca sa usporenim mentalnim razvojem, autizmom, problemima u ponašanju i emocionalnim poremećajima često imaju poteškoće u odgovarajućoj interakciji sa vršnjacima i stoga su izloženi riziku za kasnije socijalne probleme. Stvaranjem prilika da deca uče i vežbaju odgovarajuće socijalne veštine, može se poboljšati dečje socijalno ponašanje, potencijalno za ceo život.

\section{Uloga vaspitača u stvaranju uslova za pozitivnu vršnjačku interakciju}

U ranom detinjstvu deca uče kroz društvenu interakciju sa vršnjacima, braćom i sestrama, roditeljima i vaspitačima (Henderson \& Atencio, 2007). U većini slučajeva, pozitivni i zadovoljavajući odnosi, kao i prijateljstva, sa vršnjacima ne nastaju samom činjenicom da su deca često okružena jedni drugima. Deca imaju mnogo strategija koje koriste za interakciju jedni sa drugima, neke od ovih strategija su odgovarajuće, dok neke nisu. Većina vaspitača susrela se sa decom koja otimaju drugima igračke, guraju se ili udaraju kako bi dobili ono što žele ili ignorišu vršnjaka koji pokušava da sa njim ostvari interakciju.

Razvoj socijalne kompetencije u okruženju vršnjaka zahteva pažnju odrasle osobe koja razume socijalne potrebe i mogućnosti dece predškolskog uzrasta i zna kako da pruži odgovarajuću podršku i intervenciju, po potrebi. Vaspitači mogu da pomognu deci da razviju socijalnu kompetenciju na razne načine. Strategija koja pomaže deci da uspostave pozitivnu vršnjačku interakciju može biti indirektna, kao na primer dizajniranje fizičkog okruženja na način koji suptilno podstiče interakciju. Sa druge strane, ponekad strategije mogu biti više direktne, kao što su neke konkretne intervencije vezane za ponašanje pojedinog deteta.

Deca u predškolskom uzrastu mogu spontano formirati igračke grupe u pravcu svojih želja, što predstavlja slobodnu dečiju igru i ujedno najprikladniji kontekst za otkrivanje vršnjačkih socijalnih interakcija (Gmitrova \& Gmitrov, 2003). Međutim, razvoj društvene interakcije vršnjaka može obogatiti odrasla osoba koja nadgleda potrebe dece u socijalnom kontekstu, razume sposobnosti dece u vršnjačkim odnosima i preduzima neophodnu intervenciju. Dizajniranje okruženja na način koji pruža naj- 
bolje uslove za razvojne potrebe dece i podržava razvoj socijalnih veština i vršnjačku interakciju na ranom uzrastu su presudni (Henderson \& Atencio, 2007). Vaspitači imaju kapacitet da razumeju izazove sa kojima se deca susreću u odnosu sa vršnjacima i mogućnost korišćenja strategija kako bi podržali pozitivnu interakciju sa vršnjacima (Moon, 2001).

Promovisanjem pozitivnih interakcija vaspitač adekvatno reaguje na potencijalno konfliktne situacije i pruža podršku deci u njihovom razrešavanju. Takođe, vaspitač na taj način uvažava i ističe vrednosti prijateljstva i neguje prijateljstvo među decom. Pored toga, uloga vaspitača je da modeluje poželjno socijalno ponašanje dece (slušanje drugog, čekanje na red, deljenje) i da ne koristi i ukazuje deci da ne koriste socijalno nepoželjne oblike ponašanja kao što je etiketiranje dece, tužakanje, ignorisanje.

Veoma je širok spektar mogućnosti delovanja na vršnjačku interakciju kroz različite aspekte okruženja. Neke od značajnih strategija koje treba primeniti kako bi se stvorili uslovi za pozitivnu vršnjačku interakciju odnose se na: emocionalnu klimu, fizičko okruženje, grupisanje dece i dečju igru.

Emocionalna klima utiče na raspoloženje dece da pozitivno i mirno komuniciraju jedni sa drugima. Deca koja se osećaju sigurno i poštovano u stanju su da usmere svoju pažnju na vršnjake. Dok, sa druge strane, deca koja su uplašena, koja se osećaju nesigurnim usmeravaju svoju snagu da se zaštite. To može značajno uticati na količinu i kvalitet energije koju deca imaju na raspolaganju da kompetentno i prijatno komuniciraju sa vršnjacima (Kemple, \& Hartle, 1997). U tom kontekstu veoma je važna uloga vaspitača u razvijanju grupnog identiteta kroz rituale, obezbeđivanje rutine i predvidljivosti, reagovanja na detetove potrebe i zajedničko formulisanje pravila grupe. Dakle, pružanje mogućnosti da se dete oseća sigurnim, kako bi moglo da stupi u produktivne i pozitivne odnose sa vršnjacima.

Kada se razmatra dizajn fizičkog okruženja u kome deca borave, postoje dva faktora povezana sa socijalnim i emocionalnim razvojem koji zahtevaju posebnu pažnju. Prvi se odnosi na strategije promovisanja uključivanja u interakciju sa vršnjacima, dok drugi podrazumeva prevenciju izazovnog ponašanja dece (Curtis, \& Carter, 2005). Na primer, kada je reč o materijalima koje deca koriste za igru, preporuka je ponuditi predmete koji promovišu društvenu igru, poput dramatičnih rekvizita za igranje i odeće ili umetničkih materijala za kolaborativne projekte. Takođe, kako bi se predupredila izazovna ponašanja dece i sprečili konflikti potrebno je obezbediti dovoljno predmeta kako bi deca mogla da izvršavaju svoje planove, a da ne budu frustrirana čekajući na ono šta žele da koriste.

Kada je reč o grupisanju dece za različite aktivnosti i igru važno je imati na umu pojedinačne karakteristike deteta kao što su temperament i samopouzdanje, jer one mogu uticati na način na koji deca razgovaraju i komuniciraju jedni sa drugima (Bovey, \& Strain, 2003). Posmatranje prirodnih interakcija među decom koja jedni druge traže kao partnere za igru je odličan način za prikupljanje informacija koje će kasnije biti korišćene za podsticanje vršnjačke interakcije. Grupisanje dece koja su slobodnija 
sa vršnjacima koji su skloni stidljivosti može olakšati interakcije i razvoj odnosa tokom aktivnosti kao što su užina ili neke zajedničke aktivnosti. Takođe, postavljanje dece sa manje razvijenim socijalnim veštinama uz ili u blizini socijalno kompetentnije dece tokom aktivnosti velikih i malih grupa je minimalno nametljiv način za podsticanje interakcije (Bovey, \& Strain, 2003). Takođe, vaspitač treba da podstiče decu da pomažu jedni druge tokom aktivnosti, igre i u praktičnim životnim situacijama, tj. da podržava deljenje znanja i umenja među decom kroz zajedničko učešće u aktivnostima $i$ ističe vrednosti kooperativne igre.

Deca predškolskog uzrasta se igraju i uživaju u igri. Igra je važna za decu ne samo zato što u njoj toliko uživaju, već i zato što igra važnu ulogu u promociji društvenog, emotivnog i kognitivnog razvoja. Tokom igre deca uče veštine koje im pomažu u interakciji sa drugom decom. Neke od socijalnih koristi igre su razvijanje empatije, saosećanja, pružanje mogućnosti izbora, razvoj neverbalnih veština, pažnje i istrajnosti (Krnjaja, 2012). Međutim, s obzirom da slobodno vreme za igru ima rizik da stvori haotično okruženje, vaspitači imaju veliku ulogu u učenju dece slobodi i odgovornosti i uspostavljanju ravnoteže između aktivnosti kojom žele da se bave i načina na koji se ponašaju tokom aktivnosti (Yang, 2000).

Sa godinama, deca često učestvuju u kooperativnoj igri sa dvoje ili više dece, sa dodeljenim ulogama i zajedničkim ciljem. Kooperativna igra je posebno važna jer omogućava deci da nauče socijalna pravila kao što su deljenje, saradnja i rešavanje sukoba. Takođe, ova vrsta igre vodi ka razvijanju prijateljstava. Socijalno-dramska igra ili igra pretvaranja je kooperativna igra i čini oko dve trećine svih glumačkih igara predškolske deca. Socijalno-dramska igra može biti sredstvo za razvoj dečijih socio-emocionalnih veština jer zahteva refleksiju, empatiju, emocionalno razumevanje i regulaciju. Igra pretvaranja pruža deci mogućnost vežbanja i sagledavanja perspektive drugih i povezuje se sa detetovim razumevanjem emocija drugih i sa visokom emocionalnom regulacijom i kompetencijom. Takođe, Pešikan i Antić (2012) navode da su igre uloga i socijalno dramske igre od ključnog značaja za socijalni razvoj deteta, jer kroz njih deca usvajaju različite uloge, pravila i obrasce ponašanja u društvu.

\section{Zaključak}

Dakle, vršnjaci igraju važnu ulogu u životu dece već na ranom uzrastu. Deca koja su na ranom uzrastu kompetentna sa vršnjacima i ona koja pokazuju prosocijalno ponašanje, imaju tendenciju prihvatanja od strane vršnjaka. Sa druge strane, jasno je da odnosi sa vršnjacima predstavljaju posebne izazove za decu koja imaju smetnje u razvoju i nedovoljno razvijene emocionalne, kognitivne i bihevioralne veštine koje su u osnovi skladne vršnjačke interakcije. Rizik za decu koja imaju rane bihevioralne i emocionalne probleme pogoršava se odbacivanjem od strane vršnjaka. Suprotno tome, čini se da rano prijateljstvo i pozitivni odnosi sa vršnjačkim grupama štite decu od kasnijih psihosocijalnih problema. 
Dakle, iako vršnjački odnosi predškolske dece mogu biti rizični, oni predstavljaju najpogodniji kontekst za razvoj socijalnih veština i osnovu za buduće psihosocijalno prilagođavanje. Baš zbog pomenutog rizika odbacivanja od strane vršnjaka, koje može imati dugoročne posledice, promovisanje vršnjačkih odnosa i podsticanje pozitivne vršnjačke interakcije već od ranog uzrasta treba da budu u fokusu kada se razmatraju, kako fizičko okruženje, tako i igra, životno praktične situacije, kao što su rutine i rituali i planirane situacije učenja. Naravno, najveću odgovornost za kreiranje takvog fizičkog i socijalnog okruženja imaju odrasli, pre svega roditelji u porodičnom kontekstu i vaspitači u predškolskim ustanovama. Iz tog razloga neophodno je razmatrati i istraživati koje su mogućnosti i potencijalne strategije odraslih kojima bi se podržala pozitivna vršnjačka interakcija, a time i dobrobit deteta.

\title{
Aleksandra Pavlović \\ PEER RELATIONSHIPS AT PRESCHOOL AGE AND CONDITIONS TO ENCOURAGE POSITIVE PEER INTERACTION
}

\begin{abstract}
The child experiences the world through the relationships he/she establishes and develops. Relationships with close adults and peers determine his or her early childhood development and learning. Peer interaction is essential for current and future psychosocial adjustment. Peers help the child master new social skills and become familiar with social norms and processes of engaging in interpersonal relationships. This topic is of particular interest today when an increasing number of children are exposed to peers long before school age through kindergartens. However, the fact that children spend much of their time together does not mean that they will develop positive interaction skills. In this context, a significant role is attached to the adult, ie. teacher. The role of educators is to foster positive peer interaction through the creation of physical and social environments, using different strategies, as well as their own example.
\end{abstract}

Key words: peers, relationships, interaction, preschool teacher, preschool age

\section{Literatura}

Bandura, A. (2002). Social Cognitive Theory in Cultural Context. Applied Psychology: An International Review, 51(2), 269-290.

Bovey, T., \& Strain, P. (2003). Using environmental strategies to promote positive social interactions. Center on the Social and Emotional Foundations for Early Learning. www. vanderbilt.edu/csefel 
Burgess, K.B., Wojslawowicz, J.C., Rubin, K.H., Rose-Krasnor, L., \& Booth-LaForce, C. (2006). Social information processing and coping styles of shy/withdrawn and aggressive children: Does friendship matter? Child Development. 77, 371383.

Collins, W. A., Maccoby, E. E., Steinberg, L., Hetherington, E. M., \& Bornstein, M. H. (2000). Contemporary research on parenting: The case for nature and nurture. American Psychologist, 55, 218-232.

Curtis, D., \& Carter, M. (2005). Rethinking early childhood environments to enhance learning. Young Children, 60(3): 34-38.

Gmitrova, V. \& Gmitrov, J. (2003). The impact of teacher- directed and child- directed pretend play on cognitive competence in kindergarten children. Early Childhood Education Journal, 30(4), 241-246.

Hay, D. F., Payne, A., \& Chadwick, A. (2004). Peer relations in childhood. Journal of Child Psychology and Psychiatry and Allied Disciplines, 45(1), 84-108.

Henderson, T. Z. \& Atencio, D. J. (2007). Integration of play, learning, and experience: What museums afford young visitors. Early Childhood Education Journal, 35, 245-251.

Kemple, K., \& Hartle, L. (1997). Getting Along: How Teachers Can Support Children's Peer Relationships. Early Childhood Education Journal, 24(3), 139-146.

Krnjaja, Ž. (2012). Igra na ranim uzrastima. U: A. Baucal (Ur.), Standardi za razvoj $i$ učenje dece ranih uzrasta u Srbiji (pp. 113-132). Beograd: Institut za psihologiju Filozofskog fakulteta Univerziteta u Beogradu.

Ladd, G. W., \& Troop-Gordon, W. (2003). The role of chronic peer difficulties in the development of children's psychological adjustment problems. Child Development, 74(5), 1344-1367.

Moon, M. (2001). Teacher perspectives on peer relation problems of young children. Asia Pacific Education Review, 2(1), 22-31.

Ostrov, J. M., \& Keating, C. F. (2004). Gender differences in preschool aggression during free play and structured interactions: An observational study. Social Development, 13(2), 255-277.

Pavlović-Brenesalović, D., Krnjaja, Ž. (2017). Osnove diversifikovanih programa predškolskog vaspitanja i obrazovanja. Beograd: Institut za pedagogiju i andragogiju, Filozofski fakultet Univerziteta u Beogradu.

Pešikan, A., Antić, S. (2012). Učenje i razvoj na ranim uzrastima. U: A. Baucal (Ur.), Standardi za razvoj i učenje dece ranih uzrasta u Srbiji (pp. 85-111). Beograd: Institut za psihologiju Filozofskog fakulteta Univerziteta u Beogradu.

Rogers, S. J., Hepburn, S. L., Stackhouse, T., \& Wehner E. (2003). Imitation performance in toddlers with autism and those with other developmental disorders. Journal of Child Psychology and Psychiatry and Allied Disciplines, 44(5), 763781. 
Rubin, K. H., Bowker, J. C., McDonald, K. L., \& Menzer, M. (2013). Peer Relationships in Childhood. In P. D. Zelazo (Ed.), The Oxford Handbook of Developmental Psychology, Vol. 2 Self and Other, Edition: 1, (pp.242-275). Publisher: Oxford University Press.

Rubin, K., Bukowski, W., \& Parker, J. (2006). Peer interactions, relationships, and groups. In W. Damon, R. Lerner, \& N. Eisenberg (Eds.,) Handbook of child psychology: Vol. 3. Social, emotional, and personality development (6th ed) (pp.571-645). New York: Wiley.

Rubin, K. H., Burgess, K. B., Dwyer, K. M., \& Hastings P. D. (2003). Predicting preschoolers' externalizing behaviors from toddler temperament, conflict, and maternal negativity. Developmental Psychology, 39(1), 164-176.

Shortt, J. W., Capaldi, D. M., Dishion, T. J., Bank, L., \& Owen, L. D. (2003). The role of adolescent peers, romantic partners, and siblings in the emergence of the adult antisocial lifestyle. Journal of Family Psychology, 17, 521-533.

Simpkins, S., \& Parke, R. (2002). Do friends and nonfriends behave differently? A social relations analysis of children's behavior. Merrill-Palmer Quarterly, 48, 263-283

Vaughn, B. E., Vollenweider, M., Bost, K. K., Azria-Evans, M. R., \& Snider, J. B. (2003). Negative interactions and social competence for preschool children in two samples: Reconsidering the interpretation of aggressive behavior for young children. Merrill-Palmer Quarterly, 49(3), 245-278.

Yang, O. S. (2000). Guiding Children`s verbal plan and evaluation during free play: An application of Vygotsky's genetic epistemology to the early childhood classroom. Early Childhood Education Journal, 28(1), 1-10. 